\title{
Effect of Medicinal Mushrooms on L-arginine/NO System in Red Blood Cells of Streptozotocin-induced Diabetic Rats
}

\author{
Taras Y. Vitak ${ }^{1, *}$, Solomon P. Wasser ${ }^{1,2}$, Eviatar Nevo $^{2}$, Natalia O. Sybirna ${ }^{3}$ \\ ${ }^{1}$ Department of Evolutionary and Environmental Biology, Faculty of Natural Science, University of Haifa, Israel \\ ${ }^{2}$ Institute of Evolution, University of Haifa, Israel \\ ${ }^{3}$ Department of Biochemistry, Faculty of Biology, Ivan Franko National University of Lviv, Ukraine
}

Copyright $(2016$ by authors, all rights reserved. Authors agree that this article remains permanently open access under the terms of the Creative Commons Attribution License 4.0 International License

\begin{abstract}
Increase of nitric oxide production resulted in the development of oxidative-nitrosative stress that is considered to be an etiological cause of many diseases, including diabetes mellitus (DM). Recently, it was found that red blood cells (RBCs) are able to produce nitric oxide (NO), and due to the ability of hemoglobin to bind to nitric oxide, are the main depot of NO. Medicinal mushrooms are widely used in the correction and treatment of many diseases, including diabetes. Our previous results showed that Agaricus brasiliensis and Ganoderma lucidum have hypoglycemic effects and improve the functional state of RBCs. In this study, the influence of submerged cultivated mycelium powder (SCMP) of the abovementioned mushrooms on the red blood cells L-arginine/NO system of streptozotocin-induced DM rats was investigated. Wistar outbread white rats were used in the study. Streptozotocin was intraperitoneal injected one time at a dose of $50 \mathrm{mg} / \mathrm{kg}$ body weight. Mushroom preparations were orally administered at a dose of $1 \mathrm{~g} / \mathrm{kg} /$ day for 14 days. We showed that administration of medicinal mushrooms SCMP to diabetic animals caused restoration of NO-synthase activity, normalized nitrite content (in case of $A$. brasiliensis), and led to nitrate growth. Therefore, treatment with mushroom mycelia normalizes the production of nitric oxide to physiological values.
\end{abstract}

Keywords Diabetes Mellitus, Streptozotocin, Red Blood Cell, L-arginine, NO, Agaricus brasiliensis, Ganoderma lucidum

\section{Introduction}

Diabetes mellitus (DM) is characterized by a slow lesion progression of both small (microangiopathy) and large (macroangiopathy) vessels. The classic trio of diabetic microangiopathies is retinopathy, nephropathy, and neuropathy. Most epidemiological investigations showed that chronic hyperglycemia is the main cause of vessel tissues damaged during diabetes mellitus. It is assumed that the detrimental effects of enhanced blood glucose levels are manifested in the intensification of oxidative stress and development of endothelial dysfunction [1]. Endothelial dysfunction is manifested in the lack of synthesis or bioavailability of nitric oxide (NO) [2] due to a reduction of its production and/or inactivation by reactive oxygen species produced either by glycated proteins or directly from vascular endothelium [3].

Nitric oxide is an unstable, high-reactive, gaseous molecule with a short half-life, which is produced by enzymatic and non-enzymatic pathways and involved in numerous metabolic pathways and transformations. Enzymatic synthesis of $\mathrm{NO}$ is controlled by different isoforms of NO-synthase (NOS) (EC 1.14.13.39), which in the presence of molecular oxygen and several cofactors (calcium ions, calmodulin, $\mathrm{NADPH} \cdot \mathrm{H}^{+}$, flavin mononucleotide, flavin adenine dinucleotide, and tetrahydrobiopterin) catalyze the conversion of L-arginine to NO and L-citrulline [4].

There are three main isoforms of NO-synthase - neuronal (NOS1 or nNOS), inducible (NOS2 or iNOS), and endothelial (NOS3 or eNOS) [1]. NOS1 and NOS3 are constitutive forms whose activity is modulated by the increase of intracellular concentration of calcium. They produced low amounts of NO that are important for physiological processes such as neuronal signaling, inhibition of the hemostatic system, and vasodilation and blood pressure control [5]. NOS2 is an inducible isoenzyme which expression controlled by inflammation and pro-inflammation mediators [4]. NO amounts synthesized by iNOS are relatively high (a magnitude of 3 orders higher than production of constitutive isoforms) and involved in defense reactions of the organism, inflammation reactions, 
oxidative-nitrosative stress, etc. [5].

In recent years the NO-dependent signaling in red blood cells and the role of hemoglobin in NO metabolism [6] were intensively discussed. To date, RBCs have been considered as a major scavenger and depot of NO. However, functional active isoforms of enzymes that structurally and functionally resemble eNOS and iNOS were found in the cells $[7,8,9]$. It is known that NO produced by RBCs is involved in cell deformation ensuring their passage through micro vessels [10]. In addition, nitric oxide can diffuse from RBC into the plasma where it inhibits the activation and aggregation of platelets, and leukocytes adhesion and migration [5].

Red blood cells also play an important role in maintenance of the nitric oxide pool in the bloodstream. Redundant NO diffuses from plasma into the cells where, with participation of hemoglobin, it converted into stable products. Thus, the interaction of nitric oxide with oxyhemoglobin leads to formation of nitrate anions and methemoglobin. Also, nitrites can interact with oxyhemoglobin [11]. Hemoglobin shows nitrite-reductase activity, which signifies the reduction of nitrites to molecular NO by deoxyhemoglobin. This reaction contributes to RBC-dependent vasodilation during hypoxia that often accompanies diabetes mellitus [11]. Except for the metabolic transformations of nitric oxide, hemoglobin is also involved in processes of its deposition. $\mathrm{NO}$ binding to the hem group of deoxyhemoglobin produced iron nitrosyl hemoglobin $(\mathrm{HbNO})$ and binding to the thiols group of globin, - formed S-nitrosohemoglobin (HbSNO). The conformational change that occurs during oxygenation of $\mathrm{HbNO}$ in the lungs is thought to induce a transfer of the $\mathrm{NO}$ to an adjacent thiol on the cysteine group of $\beta$-chain, producing $\mathrm{HbSNO}$ [3]. S-nitrosohemoglobin is a vasodilator whose activity is allosterically regulated by $\mathrm{O}_{2}$. During deoxygenation of $\mathrm{HbSNO}$, its conformational transition (from R-state to T-state) initiates the releasing of NO [12].

NO deficiency leads to the impairment of such processes as fibrinolysis, interaction of platelets and leukocytes with vessel walls, regulation of vessels tone, proliferation of smooth muscle cells, blood pressure homeostasis, etc. [13]. Equally damaging is the overproduction of nitric oxide produced mainly by iNOS activation [14, 15]. Excessive NO synthesis can lead to the development of nitrosative stress caused by reactive nitrogen species, primarily peroxinitrite $[16,17]$. The latter caused nitration and nitrosilation of protein, lipid peroxidation, DNA damage, and ultimately leads to cell death $[1,18]$.

The use of preparations from medicinal herbs and mushrooms become more popular every year. Unlike synthetic medicine used in modern pharmacotherapy, natural preparations do not cause disturbances and complications because of its natural origin and composition. To date, there are a few investigations that indicate the medicinal mushrooms' use in regulation of NO synthesis and secretion by the cell involved in immunological responses (i.e., leukocytes, macrophages). In all of these studies, investigators used some extract or specific substances received from medicinal mushrooms [19]. But there is no data about the use of mushrooms in the regulation of nitric oxide synthesis by RBCs both in normal conditions and under different pathologies.

Therefore, the aim of the present study was to investigate the effect of submerged cultivated mycelium powder (SCMP) of Agaricus brasiliensis and Ganoderma lucidum on oxidative pathway of L-arginine metabolism and content of stable NO-metabolites in red blood cells of rats with streptozotocin-induced diabetes mellitus

\section{Materials \& Methods}

\subsection{Mushroom Material}

Mushrooms' strains were obtained from the culture collection of Mycolivia Ltd. (Israel) and maintained on malt extract agar plates at $5^{\circ} \mathrm{C}$. Chemical composition and nutritional value of submerged culture mycelia of mushrooms were presented [20]. Condition of mushroom cultivation and receipt of biomass are described in our previous article [21].

\subsection{Animals and Experimental Design}

The study was conducted on Wistar outbred white male rats weighing $150-180 \mathrm{~g}$. The animals had free access to food and water in normal conditions of the vivarium (a 12-hour light and darkness cycle at $22^{\circ} \mathrm{C} \pm 2{ }^{\circ} \mathrm{C}$ and $55 \% \pm 5 \%$ relative humidity). The experiments were performed in accordance with ethical standards set forth by the First National Congress on Bioethics (Kyiv, Ukraine, 2001), which conforms to the provisions of the European Convention for the Protection of Vertebrate Animals Used for Experimental and Other Scientific Purposes Directive of 24 November 1986 (86/609/ECC) and were approved by the Bioethics Committee of Ivan Franko National University of Lviv, and to the Law of Ukraine "On protection of animals from cruel behavior" of 26.02.2006.

The rats were divided into the following six groups: $1-$ control $(\mathrm{CON}) ; 2$ - control animals treated with $A$. brasiliensis powder (COA); 3 - control animals treated with G. lucidum powder (COG); 4 - streptozotocin-induced diabetic rats (STZ); 5 - streptozotocin-induced diabetic rats treated with $A$. brasiliensis powder (STA); 6 streptozotocin-induced diabetic rats treated with G. lucidum powder (STG). Each group consisted of 6-8 rats. DM was induced by a single intraperitoneal injection of streptozotocin (Sigma, USA) in the dose of $50 \mathrm{mg} / \mathrm{kg}$ of body weight dissolved in $10 \mathrm{mM}$ citrate buffer $(\mathrm{pH}=5.5)$. Blood glucose concentrations were measured in 72 hours and in 14 days after the induction of DM by the glucose oxidase method with the help of a reagent kit ("Felisit-Diagnostyka", Ukraine). The animals used in the experiment had glucose levels exceeding $14 \mathrm{mM}$.

On day 15 , after the diabetic induction, the rats began to receive a daily dose of $1 \mathrm{ml}$ of powdered mycelia of the 
mushrooms prepared in saline in the ratio corresponding to a dose of $1 \mathrm{~g} / \mathrm{kg}$ of body weight.

The preparation was administered perorally using feeding needles for 14 days. On day 15 of the SCMP administration (day 30 of experiment), the rats were decapitated under light ether anesthesia. Blood samples were taken for the study with the addition of heparin (heparin: whole blood $50 \mathrm{U}: 1$ $\mathrm{ml})$.

\subsection{Preparation of Red Blood Cell Lysates}

Three times washed RBCs were hemolyzed by distilled water in the ratio 1:2. Obtained hemolysates were used for determination of L-arginine, nitrite, and nitrate anions content and for measure of NO-synthase activity. Deproteinization of lysates performed by adding $96 \%$ ethanol in the ratio $1: 2$ was followed by centrifugation for 20 $\min$ at $3,000 \mathrm{rpm}[22]$.

\subsection{Determination of Total NO-synthase Activity}

Total NOS activity was determined in RBC lysates. The samples $(0.02 \mathrm{ml})$ were mixed with $0.21 \mathrm{ml}$ of the substrate mixture (phosphate buffer saline ( $\mathrm{pH}$ 7.4); $1 \mathrm{mM} \mathrm{MgCl} 2,1$ $\mathrm{mM} \mathrm{CaCl} 2,30 \mu \mathrm{M} \mathrm{L}$-аргінін, $\left.100 \mu \mathrm{M} \mathrm{NADPH} \cdot \mathrm{H}^{+}\right)$for 30 min at $37^{\circ} \mathrm{C}$. Protease inhibitors $(0.5 \mathrm{mM}$ aprotinin (Sigma, USA), pepstatyn (Sigma, USA) and $10 \mathrm{mM}$ phenylmethanesulfonyl fluoride (Sigma, USA)) were added to substrate mixture directly before the measurement. The reaction was stopped by $96 \%$ ethanol and followed by centrifugation for $20 \mathrm{~min}$ at $2,500 \mathrm{rpm}$. The supernatant $(0.1$ $\mathrm{ml}$ ) was mixed with Griess reagent $(0.1 \mathrm{ml})$. The obtained mixture was incubated for $30 \mathrm{~min}$ at $37^{\circ} \mathrm{C}$. Control samples consisted from substrate mixture with protease inhibitors and deproteinized lysate. Extinction was measured at $540 \mathrm{~nm}$. The results were calculated using a calibration graph for standard solutions of sodium nitrate. NOS activity was expressed in pmol of newly produced $\mathrm{NO}_{2}{ }^{-}$per min per $1 \mathrm{mg}$ of protein [23].

\subsection{Determination of L-arginine Content}

The concentration of L-arginine was measured in red blood cells and plasma using the method described by Weber [24]. Briefly, $1 \mathrm{ml}$ of sample was mixed with $0.2 \mathrm{ml}$ of $10 \%$ $\mathrm{NaOH}$ and $0.2 \mathrm{ml}$ of $0.02 \% \alpha$-naphtol alcohol solution added one after another. After a 5 -min incubation, $0.04 \mathrm{ml}$ of $2 \%$ sodium hypobromite solution was added. Next, after $15 \mathrm{~s}$, a $0.2 \mathrm{ml}$ of $40 \%$ urea solution was added. Extinction was measured at $500 \mathrm{~nm}$ after a 5 -min incubation. The control sample contained $1 \mathrm{ml}$ of distilled water instead of lysate. Concentration of amino acid was determined according to calibration graphs for standard L-arginine solutions. All reagents were cooled and procedures were conducted at $0^{\circ} \mathrm{C}$.

\subsection{Nitrite-anion Content Determination}

$0.1 \mathrm{ml}$ of deproteinizated supernatant of red blood cells was mixed with $0.1 \mathrm{ml}$ of Griess reagent (consisted of equal parts of $\quad 0.05 \% \quad \mathrm{~N}$-(1-naphthyl)-ethylenediamine dihydrochloride and $1 \%$ solution of sulfanilamide in $5 \% \mathrm{HCl}$ ) and incubated mixture for $30 \mathrm{~min}$ at $37^{\circ} \mathrm{C}$. Control samples contained the same amount of distilled water instead of the supernatant. Extinction was measured at $540 \mathrm{~nm}$. The results were calculated by the calibration graph, which was built using standard solutions of sodium nitrite [25].

\subsection{Determination of Nitrate-anion Concentrations}

The concentration of nitrite anions was calculated as a difference between total content of nitric oxide metabolites and content of nitrite anions. To determine total content of stable NO metabolites, a prior reduction of nitrates to nitrite was performed. Vanadium (III) chloride was used as a reducer. Deproteinized supernatant, $\mathrm{VCl}_{3}$ and Griess reagent were mixed in equal amounts. The mixture was incubated for $30 \mathrm{~min}$ at $37^{\circ} \mathrm{C}$. The control sample contained distilled water instead of the supernatant. Extinction was measured at 540 $\mathrm{nm}$. The results were calculated using a calibration graph for standard solutions of sodium nitrate [25].

All measurements were carried out in 96-well flat-bottom plates using the microplate spectrophotometer Epoch (Biotek, USA).

The concentration of protein in the samples was estimated by the Lowry method [26]

\subsection{Statistical Analysis}

All results were displayed as means \pm SEM. The Student $t$-test was used for the evaluation of the differences between treatment groups and control groups. After a $t$-value is determined, $p$-value can be found using a table of values from Student's $t$-distribution. $\mathrm{P}<0.05$ was considered significant.

\section{Results}

Our investigations showed an increase of total NO-synthase activity by $36.5 \%$ in rats with streptozotocin-induced diabetes mellitus compared with controls (Fig. 1).

Administration of SCMP of $A$. brasiliensis to CON group did not cause changes of enzyme activity, whereas administration of G. lucidum SCMP led to decreased total NO-synthase activity by $39.0 \%$ compared with control animals (Fig. 1). A. brasiliensis and G. lucidum SCMP administered to diabetic rats led to the lowering of total NOS activity by $30.1 \%$ and $22.0 \%$, respectively, compared with the STZ group (Fig. 1). 


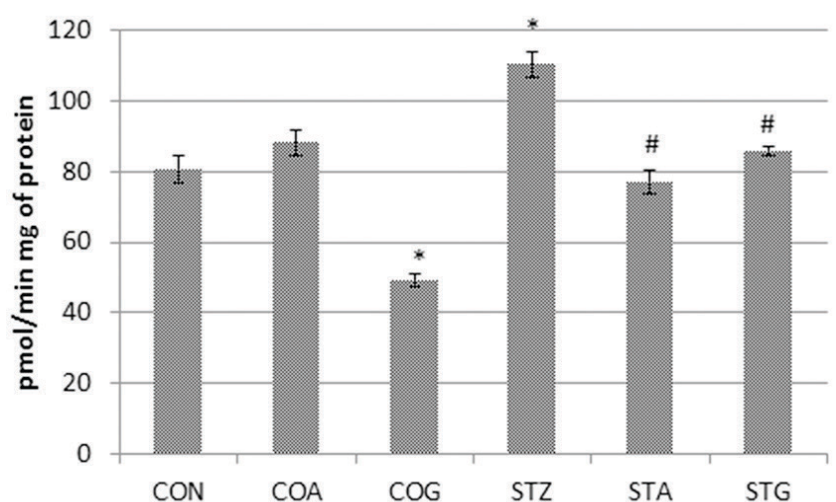

Figure 1. Total NO-synthase activity in rat RBCs in control (CON), streptozotocin-induced diabetic (STZ) and SCMP-treated groups. Values expressed as the means \pm SEM ( $\mathrm{n}=6-8$ per group). NOS activity was expressed in pmol of newly formed $\mathrm{NO}_{2}^{-} / \mathrm{min}$ per $1 \mathrm{mg}$ of protein ${ }^{*}-$ $\mathrm{P}<0.05$, all groups vs. CON group. ${ }^{*}-\mathrm{P}<0.05$, all groups vs. STZ group. $\mathrm{COA}$ - control animals treated with $A$. brasiliensis powder; $\mathrm{COG}$ - control animals treated with G. lucidum powder; STA - streptozotocin-induced diabetic rats treated with $A$. brasiliensis powder; STG streptozotocin-induced diabetic rats treated with G. lucidum powder.
Despite the strengthening of oxidation conversion of L-arginine in $\mathrm{RBC}$, the content of this amino acid was increased by $22.2 \%$ in the red blood cells of diabetic rats compared with healthy animals (Fig. 2A). However, it should be noted that concentration of L-arginine in plasma of diabetic animals did not change (Fig. 2B).

In the COA group we observed the reduction of L-arginine content in RBC (by 34.9\%) whereas in the COG group this parameter did not change compared with control animals (Fig. 2A). L-arginine concentration in plasma of the abovementioned groups was at the same level as that in the CON group (Fig. 2B).

In diabetic rats administration of $A$. brasiliensis did not cause changes in the intracellular content of L-arginine whereas plasma concentration of this amino acid increased by $8.5 \%$ compared with non-treated diabetic animals. $G$. lucidum SCMP administration to diabetic animals caused decreases in L-arginine concentrations both in RBCs (by $32.5 \%$ ) and plasma (by 13.6\%) compared with STZ group (Fig. 2).
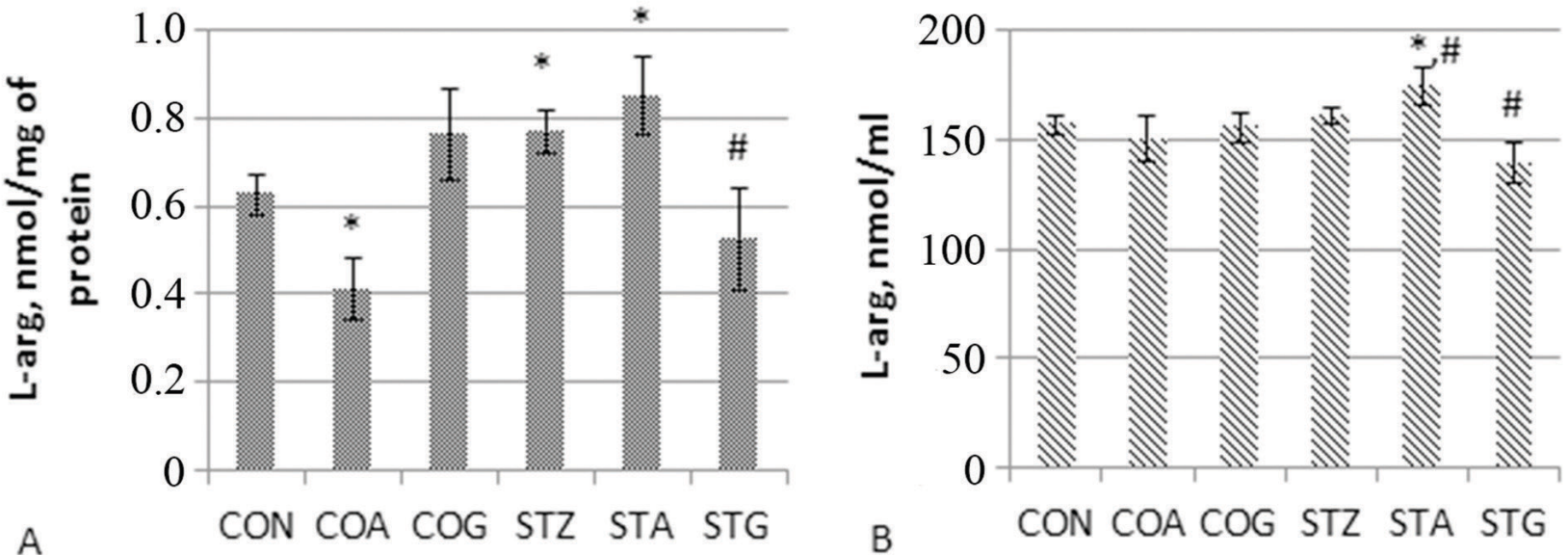

Figure 2. Concentration of L-arginine in red blood cells (A) and plasma (B) of control (CON), streptozotocin-induced diabetic (STZ), and SCMP-treated rats. Values expressed as the means $\pm \mathrm{SEM}\left(\mathrm{n}=6-8\right.$ per group). ${ }^{*}-\mathrm{P}<0.05$, all groups vs. $\mathrm{CON}$ group. ${ }^{*}-\mathrm{P}<0.05$, all groups vs. STZ group. COA - control animals treated with A. brasiliensis powder; COG - control animals treated with G. lucidum powder; STA - streptozotocin-induced diabetic rats treated with A. brasiliensis powder; STG - streptozotocin-induced diabetic rats treated with G. lucidum powder. 
The main product of the NO-synthase reaction is nitric oxide. Because of its short half-life, direct determination of the NO content is quite complicated and almost impossible. Consequently, to assess the effectiveness of NO synthesis levels of nitrites and nitrates (end stable metabolites of nitric oxide) are measured. Moreover, their levels are a clinical indicator of NO metabolism [27].

The content of nitrite anions decreased by $17.6 \%$ and the nitrates level increased by $19.1 \%$ in diabetic animals compared with control group (Table 1). Administration of the medicinal mushroom SCMP to control animals showed oppositional changes of nitrite and nitrate anions content. We observed significant growth of $\mathrm{NO}_{2}^{-}$in the COA group (by $24.6 \%$ ) while levels of nitrate did not change compared with control rats. In the COG group nitrite anions content stayed at the same level as in the CON group while concentration of $\mathrm{NO}_{3}{ }^{-}$increased by $34.7 \%$ (Table 1 ).

The renewal of nitrite anions concentration to control values has been observed in diabetic rats treated by $A$. brasiliensis SCMP, whereas G. lucidum administration did not cause changes of this index (Table 1). But, we observed a significant increase of nitrate concentration in red blood cells of STA and STG groups compared with both control and untreated diabetic animals (Table 1).

Table 1. Content of stable metabolic products of $\mathrm{NO}$ in RBCs of control, diabetic, and SCMP-treated rats

\begin{tabular}{|c|c|c|}
\hline & $\mathrm{NO}_{2}, \mathrm{pmol} / \mathrm{mg}$ of protein & $\mathrm{NO}_{3}, \mathrm{pmol} / \mathrm{mg}$ of protein \\
\hline $\mathrm{CON}$ & $169.01 \pm 4.35$ & $63.02 \pm 3.10$ \\
\hline $\mathrm{COA}$ & $210.59 \pm 4.77^{*}$ & $70.94 \pm 8.30$ \\
\hline $\mathrm{COG}$ & $171.34 \pm 5.39$ & $84.88 \pm 5.29^{*}$ \\
\hline $\mathrm{STZ}$ & $139.23 \pm 4.70^{*}$ & $75.05 \pm 4.27^{*}$ \\
\hline STA & $172.14 \pm 5.26^{\#}$ & $103.27 \pm 6.66^{*}, \#$ \\
\hline STG & $132.69 \pm 5.44^{*}$ & $128.12 \pm 2.99^{*, *}$ \\
\hline
\end{tabular}

Values are expressed as the means \pm SEM ( $n=6-8$ per group). * $-\mathrm{P}<0.05$, al groups vs. CON group. ${ }^{\#}-\mathrm{P}<0.05$, all groups vs. STZ group. $\mathrm{CON}-$ control animals; $\mathrm{COA}$ - control animals treated with $A$. brasiliensis powder; $\mathrm{COG}-$ control animals treated with G. lucidum powder; STZ streptozotocin-induced diabetic animals; STA - streptozotocin-induced diabetic rats treated with $A$. brasiliensis powder; STG streptozotocin-induced diabetic rats treated with G. lucidum powder.

\section{Discussions}

NO-synthase has three main isoforms and it was shown that in red blood cells there are at least two functioning types of the enzyme [7,9]. According to the literature data, it could be assumed that enhancement of total NOS activity was due to increased activity of the inducible isoform of enzyme. Inhibition of constitutive NOS and activation of inducible NOS under diabetes mellitus and other pathologies (i.e., cardiomyopathy) were observed by other authors $[9,16,22]$. Administration of medicinal mushrooms SCMP revealed normalization of total NO-synthase activity in diabetic animals. Obtained results can be explained by the reduction of iNOS activity caused by active compounds that are in the mycelium of investigated powders. In one study it was shown that extracts received from $G$. lucidum led to the lowering of iNOS mRNA expression in human monocyte cells stimulated by lipopolysaccharide [28]. Triterpens obtained from this mushroom inhibit secretion of nitric oxide in macrophage cell lines [29].

L-arginine as the main substrate for NOS is a natural biological source of $\mathrm{NO}$ and at the same time is a limiting factor of NO synthesis [30]. It was shown that the lack of this amino acid in cells leads to reduction of nitric oxide synthesis by NOS and facilitates the switching of the enzyme to produce the superoxide anion radical [31]. The latter interacts with NO to form peroxynitrite, which further depletes the pool of available NO in the cell [17]. The lack and reduced bioavailability of L-arginine causes numerous defects, i.e., endothelial dysfunction, atherosclerosis, cardiovascular diseases, etc. [32].

Increased content of arginine in RBCs of diabetic rats can be explained by its transport from plasma, intracellular synthesis from L-citrulline (re-synthesis) and, to a lesser extent, intracellular proteolysis [33]. Re-synthesis of $\mathrm{L}$-arginine is an important mechanism of maintenance of $\mathrm{NO}$ synthesis especially in cells expressed iNOS [30]. Enhancement of the arginine pool in cells can be connected also with impairment of the functionality of other enzymes involved in the metabolism of this amino acid (i.e., arginase) [34]. During development of diseases (such as uremia and cardio deficiency), transport of L-arginine in RBC increased due to adaptive increases in the activity of the cationic amino acid transport system $\mathrm{y}^{+}$[35]. Increased NO synthesis leads to depletion of $\mathrm{L}$-arginine concentration in the cells. Together with the accumulation of L-arginine metabolism by-products, these changes can become a trigger for activating amino acid transport from plasma into the cells [35].

In spite of total NOS activity growth, we observed a reduction of nitrite-anions concentration and an increase of nitrate-anions content in RBCs of animals with diabetes mellitus. NO is a multifunctional molecule in the cell. Despite increased synthesis, there are many ways of its inactivation. In particular, NO can interact with reactive oxygen species, which concentrations increase significantly during diabetes and form reactive nitrogen species. The latters are well-known and powerful oxidants, which play a role in the oxidative-nitrosative stress intensification [36]. Nitric oxide can also bind with different forms of hemoglobin to form nitrosyl hemoglobin and S-nitrosohemoglobin (which are potential sources of NO) or oxidize by oxyhemoglobin to nitrate [37]. Increased concentration of nitrate anions in RBC showed evidence of an intensification of $\mathrm{NO}$ oxidation processes.

Administration of medicinal mushrooms to diabetic rats led to restoration of nitrite anion levels (only in STA group) and to increased content of nitrates in both STA and STG groups. There are two possible ways of influence of biologically active compounds of medicinal mushroom mycelium on L-arginine/NO system. The first one is an 
inhibition of nitric oxide formation, which is associated with influence of the compounds on NO-synthase gene expression and/or NOS activity (in particular its inducible isoform, activity of which is increased during different pathologies). Such effects are mediated by the antioxidant properties of medicinal mushrooms, mainly through the inhibition of superoxide anion production and reactive oxygen species. The second mechanism is a direct scavenging of NO [38]. This facilitates the decrease of nitric oxide content and thus inhibition of reactive nitrogen species formation. All these processes lead to the suppression of oxidative-nitrative stress which is a cause of diabetes mellitus development.

Compounds that may be responsible for above-mentioned effects include low-molecular components such as tocopherol, ergosterol, fenol compounds, triterpenoids etc.. These compounds can inhibit the formation of reactive oxygen species and neutralize free radicals. According to the literature data mycelium of medicinal mushrooms is rich in metal ions (in particular copper and zinc ions) [20]. These ions are present in the active sites of enzymes providing the functional of enzymatic link of the antioxidant defense system. In addition, there are publications that demonstrate antioxidant properties of high-molecular compounds, in particular $\alpha$-glucan [39].

\section{Conclusions}

Development of streptozotocin-induced diabetes mellitus is accompanied by the growth of total NO-synthase activity and content of L-arginine in red blood cells of rats. These results indicate the suppression of non-oxidative pathway of L-arginine metabolism and can be caused by inhibition of arginase functionality [35]. Reduction of nitrite-anion content can be caused by their intensified oxidation to nitrate-anions and/or use of NO in reaction of reactive nitrogen species formation (in particular peroxynitrite). Together with reactive oxygen species, synthesis of which is intensified under diabetes, they facilitate the development of oxidative-nitrosative stress.

Administration of SCMP of A. brasiliensis and G. lucidum medicinal mushrooms to diabetic animals had positive corrective effect, which manifested in recovery of total NOS activity to control values and, thus, facilitated the reduction of NO overproduction. Such effect could be explained by the presence of bioactive compounds in mycelium of mushrooms which possess antioxidant properties. Thus, these compounds are able to inhibit the formation of reactive oxygen and nitrogen species and therefore suppress the development of oxidative-nitrosative stress.

\section{REFERENCES}

[1] Heltianu C, Guja C. Role of nitric oxide synthase family in diabetic neuropathy. J Diabetes Metab. 2011; S5: 002.
doi:10.4172/2155-6156.S5-002.

[2] Cockcroft JR, Webb DJ, Wilkinson IB. Arterial stiffness, hypertension and diabetes mellitus. J Hum Hypertens. 2000; 14: 377-380.

[3] James PE, Lang D, Tufnell-Barret T, Milsom AB, Frenneaux MP. Vasorelaxation by red blood cells and impairment in diabetes. Circ Res. 2004; 94: 976-983.

[4] Chen K, Pittman RN, Popel AS. Nitric oxide in the vasculature: where does it come from and where does it go? A quantitative perspective. Antioxid Redox Signal. 2008; 10(7): 1185-1198.

[5] Cortese-Krott MM, Kelm M. Endothelial nitric oxide synthase in red blood cells: key to a new erythrocrine function? Redox Biol. 2014; 2: 251-258.

[6] Owusu BY, Stapley R, Honavar J, Patel RP. Effects of erythrocyte aging on nitric oxide and nitrite metabolism. Antioxid Redox Signal. 2013; 19(11):1198-1208.

[7] Jubelin BC, Gierman JL. Erythrocytes may synthesize own nitric oxide. Am J Hypertens. 1996; 9: 1214-1219.

[8] Kang ES, Ford K, Grokulsky G, Wang YB, Chiang TM, Acchiardo SR. Normal circulating adult human red blood cells contain inactive NOS proteins. J Lab Clin Med. 2000; 135: 444-451.

[9] Kosiakova GV, Gulaya NM. The N-stearoylethanolamine effect on the NO-synthase way of nitrogen oxide formation and phospholipid composition of erythrocyte membranes in rats with streptozotocin diabetes (article in Ukrainian). Ukr Biokhim Zh. 2007; 79(6):53-59.

[10] Kleinbongard P, Schulz R, Rassaf T, Lauer T, Dejam A, Jax T, Kumara I, Gharini P, Kabanova S, Ozüyaman B, Schnürch HG, Gödecke A, Weber AA, Robenek M, Robenek H, Bloch W, Rösen P, Kelm M. Red blood cells express a functional endothelial nitric oxide synthase. Blood. 2006; 107: 2943-2951.

[11] Dejam A, Hunter CJ, Pelleteir MM, Hsu LL, Machado RF, Shiva S, Power GG, Kelm M, Gladwin MT, Schechter AN. Erythrocytes are the major intravascular storage sites of nitrite in human blood. Blood. 2005; 106(2):734-739.

[12] Halpin ST, Anderson KB, Vogel PA, Spence DM. The red blood cell and nitric oxide: derived, stimulated, or both? Open Nitric Oxide J. 2011; 3: 8-15.

[13] Dellamea BS, Leitão CB, Friedman R, Canani LH. Nitric oxide system and diabetic nephropathy. Diabetol Metab Syndr. 2014; 6: 1-17.

[14] Lee HY, Noh HJ, Gang JG, Xu ZG, Jeong HJ, Kang SW, Choi KH, Han DS. Inducible nitric oxide synthase (iNOS) expression is increased in lipopolysaccharide (LPS)-stimulated diabetic rat glomeruli: Effect of ACE inhibitor and angiotensin II receptor blocker. Yonsei Med J. 2002; 43(2):183-192.

[15] Renuka P, Naveen CR. Serum $\mathrm{NO}_{x}$ and red blood cells lysate SOD levels in diabetic patients and their relation with duration of diabetes mellitus. Asian J Pharm Clin Res. 2014; 7(5):220-221.

[16] Yolkina N, Konoshenko S, Kotsuruba A. Indexes of nitric oxide metabolism in erythrocytes of patients with 
cardiomyopathy. (article in Ukrainian) Exp Clin Physiol Biochem J. 2014; 1: 53-58.

[17] Naveen CR, Renuka P. Nitric oxide in diabetic patients and its relation with HbA1c. IJPCR. 2014; 6(2):146-148.

[18] Cowell RM, Russell JW. Nitrosative injury and antioxidant therapy in the management of diabetic neuropathy. J Investig Med. 2004; 52(1):33-44.

[19] Rubel R, Dalla Santa HS, Bonatto SJR, Bello S, Fernandes LC, Bernardi RD, Gern J, Santos CMA, Soccol CR. Medicinal mushroom Ganoderma lucidum (Leyss: Fr) Karst. Triggers immunomodulatory effects and reduces nitric oxide synthesis in mice. J Med Food. 2010; 13(1):142-148.

[20] Cohen N, Cohen J, Asatiani MD, Varshney VK, Yu HT, Yang YC, Li YH, Mau JL, Wasser SP. Chemical composition and nutritional and medicinal value of fruit bodies and submerged cultured mycelia of culinary-medicinal Higher Basidiomycetes mushrooms. Int J Med Mushrooms. 2014; 16(3):273-291.

[21] Vitak TY, Wasser SP, Nevo E, Sybirna NO. The effect of the medicinal mushrooms Agaricus brasiliensis and Ganoderma lucidum (Higher Basidiomycetes) on the erythron system in normal and streptozotocin-induced diabetic rats. Int $\mathrm{J}$ Med Mushrooms. 2015; 17(3): 277-286.

[22] Ferents IV, Brodyak IV, Lyuta MYa, Burda VA, Fedorovych AM, Sybirna NO. The effect of agmatine on L-arginine metabolism in erythrocytes under streptozotocin-induced diabetes in rats. (article in Ukrainian) Ukr Biokhim Zh. 2012;84(3):55-62.

[23] Dawson J, Knowles RG. A microtiter-plate assay of nitric oxide synthase activity. Mol Biotechnol. 1999; 12: 275-279.

[24] Weber CJ. A modification of Sakaguchi's reaction for the quantitative determination of arginine. J Biol Chem. 1930; 86: 217-222.

[25] Miranda KM, Espey MG, Wink DA. A rapid, simple spectrophotometric method for simultaneous detection of nitrate and nitrite. Nitric Oxide. 2001; 5(1):62-71.

[26] Lowry OH, Rosebrough NJ, Farr AL, Randall RJ. Protein measurement with the Folin phenol reagent. J Biol Chem. 1951; 193: 265-275.

[27] Burke T. Part 3: Nitric oxide metabolism in diabetic patients. Available online: http://www.anodynetherapy.ca/clinical.html.

[28] Woo CWH, Man RYK, Siow YL, Choy PC, Wan EWY, Lau CS, O K. Ganoderma lucidum inhibits inducible nitric oxide synthase expression in macrophages. Mol Cell Biochem.
2005; 275: 165-171.

[29] Kuo MC, Weng CY, Ha CL, Wu MJ. Ganoderma lucidum mycelia enhance innate immunity by activating NF-kappaB. J Ethnopharmacol. 2006; 103: 217-222.

[30] Hattenbach LO, Allers A, Klais C, Koch F, Hecker M. L-arginine-nitric oxide pathway-related metabolites in the aqueous humor of diabetic patients. Invest Ophthalmol Vis Sci. 2000; 41(1):213-217.

[31] Xia Y. Superoxide generation from nitric oxide synthases. Antioxid Redox Signal. 2007;9(10):1773-1778.

[32] Lorin J, Zeller M, Guilland JC, Cottin Y, Vergely C, Rochette L. Arginine and nitric oxide synthase: regulatory mechanisms and cardiovascular aspects. Mol Nutr Food Res. 2014; 58: 101-116.

[33] Hecker M, Sessa WC, Harris HJ, Anggard EE, Vane JR. The metabolism of L-arginine and its significance for the biosynthesis of endothelium-derived relaxing factor: cultured endothelial cells recycle L-citrulline to L-arginine. Proc Natl Acad Sci USA. 1990; 87: 8612-8616.

[34] Brunini TMC, Yaqoob MM, Roberts NB, Ellory JC, Moss MB, Siqueira MAS, Mann GE, Mendes Ribeiro AC. Characterization of cationic amino acid transport systems in rat erythrocytes: lack of effect of uraemia on L-arginine influx. Clin Exp Pharmacol Physiol. 2006; 33: 702-707.

[35] Mendes Ribeiro AC, Bruninia TMC, Ellorya JC, Mann GE. Abnormalities in L-arginine transport and nitric oxide biosynthesis in chronic renal and heart failure. Cardiovasc Res. 2001; 49: 697-712.

[36] Nader MM, Eissa LA, Gamil NM, Ammar ESM. Effect of nitric oxide, vitamin $\mathrm{E}$ and selenium on streptozotocin induced diabetic rats. Saudi Pharm J. 2007; 15(1):23-32.

[37] Sybirna NO, Lyuta MYa, Klymyshyn NI. Molecular mechanisms of nitric oxide deposition in erythrocytes. (article in Ukrainian) Studia Biologica. 2010; 4(1):143-160.

[38] Quaadros Gomes BA, da Silva LF, Quadros Gomes AR, Moreira DR, Dolabela MF, Santos RS, Green MD, Carvalho EP, Percario S. N-acetyl cysteine and mushroom Agaricus sylvaticus supplementation decreased parasitaemia and pulmonary oxidative stress in a mice model of malaria. Malaria J. 2015; 14: 202. doi: 10.1186/s12936-015-0717-0.

[39] Lei H, Zhang M, Wang Q, Guo S, Han J, Sun H, Wu W. MT- $\alpha$-glucan from the fruit body of the maitake medicinal mushroom Grifola frondosa (higher Basidiomyetes) shows protective effects for hypoglycemic pancreatic $\beta$-cells. Int J Med Mushrooms. 2013; 15(4):373-381. 